\title{
La unificación del Derecho Cambiario
}

\author{
Andrés León Montalbán.
}

Es en el campo del derecho comercial en donde la tendencia hacia. ‘a unificación legislativa puede mostrar algunos frutos. El carácter universal de las 'relaciones comerciales, su ascendrado cosmopolitismo, han reclamado y permitido obtener nòrmas reguladoras comunes a través de diferentes latitudes, que han venido a producir un saludable y armónico desarrollo del mundo de los negocios. Podemos afirmar, sin temor a equivocarnos, que ninguna otra rama del derecho privado ofrece mayores perspectivas de unificación que el derecho. comercial, en atención a la naturaleza de los fenómenos que regula.

Ahora bien, entre las relaciones mercantiles a cuya legislación aniversal se ha tendido, son las relaciones cambiarias las que mayormente han concitado la atención, tanto de parte de las instituciones de carácter privado de cada país, cuanto de parte de los organismos esratales; habiéndose arribado a conclusiones definitivas que representan el esfuerzo de varios congresos y conferencias internacionales.

$\mathrm{El}$ comercio internacional tiene en la letra de cambio uno de sus mas eficaces instrumentos, ya que ésta, actuando como medio de pago, permite establecer las compensaciones impuestas por la necesidad de evitar el desplazamiento de grandes cantidades de numerario entre países distintos, y de establecer un justo equilibrio en la balanza de importaciones y exportaciones, de modo que se reflejen en un armónlico desenvolvimiento de la economía mundial. Y es que en el comercio internacional funciona la compensación casi en idéntica formà que la verificada en el orden interno nacional por los clearing houses, debido a la aplicación del principio de que las ventas y compras entre países distintos deben guardar proporciones semejantes.

Pero a pesar de los beneficios que desde todo punto de vista reporta para el incremento de las transacciones comerciales, la letra de cambio no es objeto de una reglamentación legal uniforme. Cada pais 
ha hecho girar su regulación legal al redeclor de normas que responden; en cada caso, a los principios básicos sustentados por uno cualquiera de los tres clásicos sistemas jurídicos que orientan el derecha positivo sobre esta materia.

Por ser un título de crédito destinado a la circulación, es su aspecto económico el que ha dejado sentir mayormente su influencia en el aspecto jurídico de él. Tal circunstancia se encuentra a tono con las características del fenómeno comercial, cuyos intereses sirve, dentro riel cual ambos aspectos: económico y jurídico marchan estrechamente midos, influenciándose reciprocamente.

Como muchos de los aspectos de la letra de cambio sólo son exjlicables mediante su relación con los hechos propios del comercio internacional, los conflictos que se suscitan como consecuencia de la risparidad de normas reguladoras cono son las adoptadas por cada Estado, han hecho sentir la imperiosa necesidad de unificar, bajo una misma tenclencia. los principios a rue se sujeta el ordenamiento lezal de la letra de cambio y de las relaciones a que da lugar, como medio de lograr un mejor desenvolvimiento y encausamiento jurídico de las relaciones comerciales.

En esta tendencia unificadora han dejado sentir su acción, en forma por demás eficaz, los Estados y las instituciones privadas de derecho.

La "National Association for the promotion of social science", d "Instituto de Derecho Internacional" y la "International Law Association" han propiciado la celebración de congresos y conferencias internacionales, en los cuales se ha debatido como cuestión capital la manera de unificar las leyes destinadas a la reglamentación de la letra de cambio y de las relaciones cambiarias, y son los votos de estos congresos y conferencias los que han ido formando la estructura de la reglamentación uniforme que hoy impera en muchos países.

Igualmente la acción del Estado propició reuniones de carácter internacional con el mismo objeto.

El Congreso jurídico de Lima de 1878, cuyos acuerdos influyeron en los que más tarde se tomaron en el Congreso de Montevideo de 1889, se ocupó, entre otras materias, de dar pautas para solucionar los conflictos que surgen como resultantes de las operaciones de cambio; pero no puede ser considerado dicho Congreso Jurídico como una manifestación especial del movimiento hacia la unificación del derechó cambiario; habiendo propendido, mas bien, a resolver dichos conflictos por medio de reglas uniformes de Derecho Internacional.

En 1885 el Congreso reunido en Amberes elaboró un proyectó de ley uniforme sobre letras de cambio. el cual fué posteriormente adoptado por el Congreso de Bruselas de 1888. 
Un año después, el Congreso de Montevideo de 1889, si bien trató de dar los medios que permitieran la solución de los conflictos jurídicos que pueden surgir entre personas que tengan el derecho de invocar, respectivamente, la legislación de dos de los Estados signatarios, no propendió en manera alguna a la unificación de las legislaciones americanas sobre letras de cambio.

Son las Conferencias Internacionales de La Haya de 1910 y 1912 las que significan el punto de partida en la laboriosa tarea de unificación de la legislación cambiaria. En la Conferencia de 1910 se formuló un extenso anteproyecto de convención sobre unificación legislativa de la letra de cambio y del pagaré a la orden y un anteproyecto de ley uniforme sobre estas dos importantísimas materias. En la Conferencia de 1912 se aprobó el texto tefinitivo de la convención y del reglamento uniforme claborados en la Conferencia anterior, que tienen la importancia de haber inspirado las reformas legislativas introducidas cn varios paises de Europa y América.

Culminación del movimiento de unificación es la ley uniforme sobre letra de cambio y pagaré a la orden, obra de la Conferencia de Ginebra celebrada entre el 13 de mayo y el 7 de junio de 1930, bajo los auspicios de la Sociedad de las Naciones.

La ley uniforme sobre letra de cambio y pagaré a la orden consta de 78 artículos distribuídos en dos títulos. El título I, que se contrae exciusivamente a la letra de cambio, comprende los 12 capítulos siguientes: De la emisión y de la forma de la letra de cambio, del endoso, de la aceptación, del aval, del vencimiento, del pago, de las acciones en caso de falta de aceptación y falta de pago, de la intervención, de la pluralidad de ejemplares y de las copias, de las alteraciones, de la prescripción y disposiciones generales.

Ell título II trata del pagaré a la orden.

Además en la Conferencia de Ginebra de 1930 se suscribieron ires convenciones adicionales. La primera contiene el compromiso de los Estados signatarios de introducir en sus territorios la ley uniforme sobre letras de cambio y pagarés a la orden. La segunda convención está destinada a dar reglas para solucionar los conflictos de leyes en materia de letras de cambio y pagarés a la orden. La tercera convención versa sobre el derecho de timbre en materia de letras de cambio y pagarés a la orden, estableciéndose en élla la supresión de la caducidad del derecho del tenedor del título como sanción por la falta 0 insuficiencia del timbrado.

El método de unificación adoptado en la Conferencia de Ginebra de 1930 responde a principios diferentes de los que orientaron los trabajos de los congresos y conferencias que le precedieron. Mientras en las conferencias y congresos anteriores se propendió a la solución 
de los problemas legislativos sobre esta materia mediante la adopción de reglas de derecho internacional privado común, en la Conferencia de Ginebra de 1930 se elaboró un derecho, un derecho uniforme sobre letras de cambio y pagarés a la orden, o sea, que los Estados signatarios de dicha Conferencia se obligaron a dar el carácter de ley nacional al ordenamiento establecido internacionalmente.

El primer país que ratificó las convenciones de Ginebra sobre letras de cambio y pagarés a la orden fué Grecia, quien adoptó la ley iniforme por ley de 9 de marzo de 1932. Posteriormente produjeron su ratificación y modificaron su legislación nacional: Alemania, Austria, Francia, Italia, Japón, Holanda, Dinamarca, Finlandiá, Noruega, Suecia y Polonia.

En Alemania la ley de 21 de junió de 1933, que empezó a regir el $1^{\circ}$ de enero de 1934 , reproduce en sus 78 primeros artículos las disposiciones de la ley uniforme de 1930.

En Austria la ley de 18 de agosto de 1932, cuyo texto es casi exactamente igual al de la ley alemana, incorporó los principios de la ley uniforme de Ginebra.

Francia derogó toda su legislación sobre letra de cambio por decreto-ley de 30 de octubre de 1935 , adoptando los principios sustentacos en la ley uniforme.

Italia hizo lo propio a mérito de la ley de 22 de diciembre de 1932 y del decreto real de 14 de diciembre de 1933 .

En virtud de la ratificación que de las convenciones de Ginebra hizo el Japón el año 1932, las disposiciones de su Código de Comercio, sobre letras de cambio, pagarés a la orden y cheques han sido sustituídas por leyes especiales. La que empezó a regir el $1^{\circ}$ de enero de 1934 introdujo en el derecho comercial japonés la ley uniforme de Ginebra.

Holanda, Dinamarca, Suecia, Nortega, Finlandia, Polonia y la ciudad libre de Dantzig introdujeron la ley uniforme en su legislación comercial nacional, por leyes de 25 de julio de 1932, 23 de marzo de 1932, 13 de mayo de 1932, 27 de mayo de 1932, 14 de julio de 1932, 28 de abril de 1936 y 9 de marzo de 1934, respectivamente.

Bélgica, Suiza, Portugal y Mónaco, aunque han ratificado los acuerdos de la Conferencia de Ginebra de 1930, no han introducido, hasta ahora, modificación alguna en su derecho positivo sobre letras de cambio y pagarés a la orden.

Dentro de un tercer grupo podemos considerar a otros países como China, Colombia, Eccuador, Guatemala, Méjico, Nicaragua, Paraguay, Turquía, Rumanía, Yugoeslavia y Venezuela, que han orientado sus novísimas legislaciones en los preceptos del Reglamento de La Haya, de 1912 o de la Convención de Ginebra de 1930. 


\section{LA UNIFICACION DEL DERECHO CAMBIARIO}

Es de advertir que países de gran volumen de importaciones y exportaciones, y que por lo mismo dejan sentir fuertemente su acción en el comercio internacional, como Inglaterra y Estados Unidos, no han hecho esfuerzo alguno para propender a una reglamentación internacional uniforme de la letra de cambio. Así, Inglaterra ha laboracio únicamente por conseguir la unificación de las reglas de derecho cambiario dentro del Reino Unido; pero en forma alguna ha propenAido al ajuste de su legislación dentro de los moldes señalados por las convenciones a que antes nos hemos referido. La Bill of Exchange Act de 1882 rige todas las cuestiones relativas a la letra de cambio, billete a la orden y cheque.

Estados Unidos por medio de la Uniform Negotiable Intruments Act ha conseguido la unificación de las reglas relativas a la letra de cambio en sus diferentes Estados; pero, al igual que Inglaterra, nó se ha plegado al movimiento de unificación internacional.

A estos esfuerzos en pro de la unificación legislativa de la letra de cambio, debemos agregar, con toda justicia, los de la Comisión Internacional de Jurisconsultos de Río de Janeiro, creada por la Tercera Conferencia Panamericana de 1906; los de la Sexta Conferencia Panamericana de La Habana de 1928, que acordó recomendar a los países de América la conveniencia de adoptar un proyecto de ley uniforme que elaboró inspirando sus normas en los preceptos contenidos en el Reglamento de La Haya, de 1912; y los de las Sétima - Octava Conferencias Internacionales Americanas.

La Sétima Conferencia Internacional Americana resolvió:

"Que el Consejo Directivo de la Unión Panamericana designara ana Comisión de Expertos, formada por cinco miembros, para que formulara un anteproyecto de unificación del derecho cambiario, tomando como base las conclusiones de las convenciones de La Haya y de Ginebra, si fuere posible aquella unificación, y en caso contrario, a fin de que aconseje el procedimiento más adecuado para reducir al mínimo posible los sistemas a que responden las distintas legislaciones sobre letras de cambio, pagarés y cheques, así como también las reservas de que se hace uso en las convenciones sobre tales materias":

En la Octava Conferencia Internacional Americana, si bien no se adoptó ningún acuerdo sobre la unificación del derecho cambiario, en :no de los proyectos elaborados por su Comisión de Asuntos Económicos se recomendaba que se aprobara, en principio, la iniciativa de la Cámara Internacional de Comercio de establecer la uniformidad en el uso de los créditos documentarios, que dió por resultado el proyecto definitivo aprobado en el Congreso de Viena de 1936, proyecto que, después de haber sido aceptado formalmente por las asociaciones bancarias de muchos países europeos, recibió, ed $1^{\circ}$ de octubre de 1938 , 
¿a adhesión de los Bancos de Estados Unidos que tramitaban esta clase de créditos. Igualmente propugnábase, en el proyecto de la Comisión de Asuntos Económicos de la Octava Conferencia Internacional Americana, el nombramiento por cada pais americano de Comisiones de Expertos en créditos documentarios, cuyos trabajos debían tener por finalidad facilitar la adhesión a las reglas y usos uniformes que sobre esta materia ha elaborado la Cámara Internacional de Comercio.

E1 crédito documentario reclama, efectivamente, una organización legal internacional uniforme y definida, $y$ sobre todo orientada en principios económicos capaces de establecer, sin violentar el aspecto puramente formal que le dé la legislación propia de cada Estado, el armónico desenvolvimiento que reclama como instrumento propio rel comercio internacional.

En la actualidad las operaciones a base de créditos documentarios han tomado gran auge, ya sea en su forma simple como en la más compleja de apertura de crédito bancario documentario, que ha venido en nuestros clías, y superando a toda espectativa, a llenar un vacio hondamente sentido para el fomento de las transalciones comerciales.

Las ventas C. I. F., F. O. B., F. A. S., C. F. y st1s variantes, utilizan en gran escala el crédito documentario.

Por último, el Segundo Congreso Sulamericano de Derecho Internacional Privado de Montevideo del año 1940. cuyos acuerdos aún no han sido ratificados, al elaborar el Tratado de Dërecho Comercial Terrestre Internacional, ha establecido también una regulación de las letras de cambio en su aspecto internacional, dando pautas para determinar los efectos jurídicos que se derivan de sus operaciones y para solucionar los conflictos que pueden surgir entre las personas que han intervenido en la negociación de éllas o de cualquier otro título a: la orden o al portador. El título VI del expresado Tratado de Derecho Comercial Terrestre Internacional (arts. 23 al 35) se ocupa de esta importantisima materia.

Como se vé, la unificación de la legislación sobre letras de cambio reviste los caracteres de una necesidad imperiosa, la cual puede ser satisfecha con un poco de buena voluntad, ya que el problema no ofrece las dificultades insalvables que se quieren encontrar, por lo menos entre los países hispano-americanos, tanto por el carácter universal del fenómeno cambiario, cuanto por la estrecha vinculación geográfica, -acial y de orientación económica y política que existe entre los países sud-americanos. 